University of San Diego

Digital USD

Spring 5-21-2018

\title{
The Physiological Effects of Exercise on California Yellowtail (Seriola dorsalis) White Muscle
}

Julie Giannini

University of San Diego

Follow this and additional works at: https://digital.sandiego.edu/honors_theses

Part of the Biology Commons

\section{Digital USD Citation}

Giannini, Julie, "The Physiological Effects of Exercise on California Yellowtail (Seriola dorsalis) White Muscle" (2018). Undergraduate Honors Theses. 51.

https://digital.sandiego.edu/honors_theses/51

This Undergraduate Honors Thesis is brought to you for free and open access by the Theses and Dissertations at Digital USD. It has been accepted for inclusion in Undergraduate Honors Theses by an authorized administrator of Digital USD. For more information, please contact digital@sandiego.edu. 
The Physiological Effects of Exercise

on California Yellowtail (Seriola dorsalis) White Muscle

\author{
A Thesis \\ Presented to \\ The Faculty and the Honors Program \\ Of the University of San Diego
}

By

Julie Anne Giannini

Biology Department

2018 


\begin{abstract}
:
California yellowtail (Seriola dorsalis) is a species of ray-finned fish that demonstrates a significant increase in muscle mass in response to sustained exercise at optimal swimming speed. In this study, three groups of yellowtail have been analyzed for a 6-month period to determine if the length of exercise affects white muscle fiber development and if these changes persist when the exercised fish have been returned to a normal "resting" condition. Gene analysis was performed to test if MyoD, a myogenic regulatory factor, was upregulated in response to exercise. To test these questions, the groups compared included a control group (not exercised), a 3-week exercise group, and a 4-week exercise group. Samples of the yellowtail white muscle were taken monthly and analyzed microscopically to measure fiber areas and to determine if any of the groups were undergoing hypertrophy or hyperplasia. Hypertrophy is arbitrarily classified as fibers $7000+\mu \mathrm{m}^{2}$ and hyperplasia is marked by presence of newly recruited fibers $(0-1000$ $\mu \mathrm{m}^{2}$ ). The results show that immediately following the exercise period, the 4 -week exercise group had the highest average fiber area $\left(3365.5 \pm 113.5 \mu \mathrm{m}^{2}\right)$ and the control group had the smallest $\left(3034.8 \pm 103 \mu \mathrm{m}^{2}\right)$. However, at the end of the 6-months, the average fiber area of the 4-week exercise, 3-week exercise, and control were more similar in size $\left(4249.4 \pm 149.2 \mu \mathrm{m}^{2}\right.$, $4046.1 \pm 134.6 \mu \mathrm{m}^{2}, 4121.4 \pm 161.7 \mu \mathrm{m}^{2}$ ) with no significant difference. When comparing the patterning of the fibers, all three groups demonstrated a general trend of hypertrophy over the 6month period. In contrast, the control group had the greatest amount of hyperplasia, but there was not a noticeable trend in the amount of fibers that were recruited over the 6-month period. MyoD was upregulated at the start of the racing procedure compared to samples that were collected one month post-exercise.
\end{abstract}




\section{Introduction:}

Fish are unique organisms with notable phenotypic plasticity, having extensive ability to grow and develop in response to external environmental stimuli (Johnston et al., 2011). One such stimulus that has been widely studied is exercise. Many researchers have hypothesized that exercise could potentially represent a natural, noninvasive, and economical approach to improve fish growth (Schwebel, 2017). With extensive research and experimentation, fish have become a powerful model for exercise training and muscle development (McClelland, 2012).

Development of fish muscle in response to exercise has important implications for the aquaculture industry. Aquaculture includes the breeding, rearing, and harvesting of fish. Aquaculture helps produce food for the marketplace and helps maintain the biodiversity of the marine ecosystem (NOAA, 2018). Many aquaculture researchers have performed experiments to test the effect of exercise on different species of fish to help maximize growth in order to increase food supply for a growing population (Schwebel, 2017).

One group of fish whose growth patterns have been widely studied is the teleost. Teleost are bony fish that are marked by their indeterminate growth and phenotypic plasticity (Froehlich et al., 2013; Johnston et al., 2011). Teleost fish are also known for their great capacity for aerobic, sustained swimming, and anaerobic, burst swimming. Swimming is a critical activity that greatly affects the size, survival, and immune health of fish (Palstra \& Planas, 2011). Swimming activity is accomplished through the activation of the skeletal muscle (Palstra et al, 2014).

There are two distinct types of skeletal muscle in teleost fish, white muscle and red muscle (Palstra \& Planas, 2011). White muscle makes up the majority of skeletal muscle $\sim 90-$ $95 \%$ of the total muscle mass and is composed of anaerobic, tightly packed glycolytic fibers that 
support burst or high-speed swimming (Johnston et al., 2011; Kiessling, Ruohonen, and Bjørnevik, 2006; Palstra \& Planas, 2011). White muscle is concentrated near the dorsal skeletal region of the fish body (Palstra \& Planas, 2011). This muscle is activated in instances such as escaping from a predator or burst swimming to capture prey. The second type of muscle, the red muscle is a minor part of the skeletal muscle located on the surface of the trunk of the fish along the lateral line (Palstra \& Planas, 2011). Red muscle is composed of aerobic, oxidative fibers, and supports sustained swimming (Kiessling et al., 2006). Red muscle is useful in swimming long distances such as during migratory season.

It is generally supported that only red fibers are recruited during sustained swimming. However, white fibers may also be recruited to a lesser extent (Palstra \& Planas, 2011). Since there is such a clear anatomical separation between the muscle masses, fiber type-specific responses to exercise can be determined more easily (McClelland, 2012).

Development of skeletal muscle in fish and other vertebrates is called myogenesis. This process in teleost fish is highly integrated. Myogenesis is regulated by a group of muscle-specific transcription factors, collectively known as the muscle regulatory factors or MRFs, and they appear to have the same functions across various species (Rehfeldt et al., 2011). There are four primary MRFs (Myf-5, MyoD, Myogenin and MRF4). Myf-5 and MyoD are required for the commitment of undifferentiated cells into a muscle lineage. Muscle fiber production in fish occurs in three distinct phases: embryonic, late embryo to early larval stages and larval to adult stages (Rehfeldt et al., 2011).

During the embryonic phase, formation of the primary myotome starts with the differentiation of a superficial layer of slow muscle fibers from mesoderm cells. After this occurs, the deep fast muscle fibers differentiate from somite cells (Rehfeldt et al., 2011; 
Rowlerson and Veggetti, 2001). During the late embryo stages the fish demonstrates stratified hyperplasia. Finally, during the adult stage, new fast twitch fibers are formed around larger muscle fibers and demonstrate a mosaic appearance (mosaic hyperplasia) (Rehfeldt et al. 2011; Rescan, 2008). Mosaic hyperplasia is the main mechanism for expanding white fiber number in the juvenile and adult stages of the majority of species, continuing until approximately $40 \%$ of the maximum fish length (Weatherley et al., 1988). Nonetheless, both hyperplastic and hypertrophic processes can account for fish muscular growth, which is controlled by intrinsic and extrinsic regulatory factors (Carpene et al., 1982; Stickland, 1983; Kiessling et al., 1990;

Fauconneau et al., 1997; Campinho et al., 2006; Silva et al., 2009).

In addition to natural growth, some species of fish are able to display patterns of indeterminate growth. Indeterminate growth is characterized by an increase in body size and muscle mass until mortality or senescence occurs (Johnston et al., 2011). Many researchers have hypothesized that indeterminate growth may be the result of the myogenic precursor cells found in adult fish skeletal muscle (Froehlich et al., 2013). The myogenic precursor cells, also known as satellite cells are essentially stem cells that are able to differentiate into muscle lineage. These cells can build and repair muscle (Palstra et al., 2014). Due to an abundance of myogenic precursor cells and the ability of fish to renew adult stem cells, it is widely supported that teleost fish can grow without any sort of peaking (Froehlich et. al, 2013). The two main mechanisms of indeterminate muscular growth in teleost fish are hypertrophy and hyperplasia (McClelland, 2012). Hypertrophy is muscle growth by an increase in cell size. In contrast, hyperplasia is muscle growth by cell division (Palstra et al., 2010).

A large body of research has supported the findings that exercise at a critical swimming speed allows fish to optimize growth performance as evidenced by hypertrophy and presence of 
a higher proportion of large fibers in exercised fish (Bugeon, Lefevre, \& Fauconneau, 2004;

Davison 1997; Johnston 1999; Johnston et al., 2011; Johnston and Moon 1980). Studies have shown that fish skeletal muscle can change in structure, morphometric composition (fiber density and size), and biochemically (enzymatic activities) in response to exercise (Davison, 1997; Johnston and Moon, 1980). Also, unlike mammals, fish muscle can continue growing as long as they have a sufficient supply of food (Weatherley and Gill, 1987). If exercised fish are able to reach a larger size at an earlier age, while also having increased survival and immune health, exercise could be a useful tool to increase aquaculture productivity (Palstra \& Planas, 2011).

Even though exercise has been shown to enhance the growth in many species of fish, the speed and length of the exercise has a large effect. Most exercise-induced growth is stimulated at or near optimal swimming speeds $\left(\mathrm{U}_{\mathrm{opt}}\right)$. $\mathrm{U}_{\mathrm{opt}}$ is defined as the speed where the cost of transport (energy spent on swimming a certain unit of distance) is at a minimum and energetic efficiency is at a maximum (Palstra \& Planas, 2015). At swimming speeds lower than $\mathrm{U}_{\mathrm{opt}}$, a substantial amount of energy is lost, while at speeds higher than $\mathrm{U}_{\mathrm{opt}}$ swimming is unsustainable, creating an oxygen debt that will cause fatigue in the fish (Palstra. et al., 2010). Endurance training and sustained swimming, which can result in hypertrophy of fish muscle lasts more than 200-minutes at a speed that requires high energy expenditure. This form of swimming is powered by aerobic metabolism and does not result in muscular fatigue (McClelland, 2012).

The model organism for many exercise studies is the zebrafish. After exercising the zebrafish for 20-days at optimal swimming speed, Palstra and Planas (2011) found that the fish demonstrated a significant increase in total body size as a result of exercise. After continuous swimming at optimal speeds, these fish showed a 5.6\% increase in body length and $41.1 \%$ 
increase in total body weight (Palstra \& Planas, 2011). The researchers also found that exerciseinduced training led to increased hypertrophy in the fast twitch, white muscle.

In an additional zebrafish study, performed by Palstra et al. (2014) the zebrafish were trained at different intensity levels, classified at either low or optimal speeds. There was a noticeable increase in red muscle fiber area and vascularization due to angiogenesis (development of blood vessels) in the exercised fish. The data also indicated that the fish that were exercised had less small fibers and a higher percentage of large fibers compared to resting (control) fish. Within the large fibers of the exercised fish, there was an increase in the total number of capillaries relative to the total area of the fiber. The researchers credited the change in weight of the red muscle, the hypertrophic patterning, and increased vascularization to genetic upregulation within the zebrafish (Palstra et al., 2014).

Palstra et al. (2015) performed an exercise study on yellowtail kingfish, again using an optimal swimming speed. At the end of the experiment, the fish that were forced to swim at the optimal speed, demonstrated an increase of $92 \%$ in body length and a $45 \%$ increase in body weight, which was comparable to the growth seen in other experiments with yellowtail kingfish (Brown et al., 2011). During the 18-day swimming experiment, the swimmers and the nonswimming group that served as the control group were fed equivalent amounts of food (Palstra et al., 2015). The increased growth in the swimming group implies lower FCR (food conversion ratio) for the swimmers. This means that there is higher feeding efficiency of the swimmers compared to the control group (Palstra, et al. 2015). The exercised fish had higher metabolic efficiency and were able to use the nutrition of the food for muscular development more than the control group. Researchers also discovered upregulation of genes associated with muscle growth and cardiac output in the exercised yellowtail kingfish compared to the control. Furthermore, 
they found that exercise does help improve efficiency of swimming, making it easier for the fish to grow and exercise. By swimming the fish at optimal speeds, the fish are able to develop a more aerobic phenotype so that they can more efficiently utilize their energy stores in the future (Palstra et al., 2015). The aerobic phenotype allows the exercised fish to demonstrate a significant increase in body mass in response to exercise (Palstra \& Planas, 2011).

Although many of these studies indicate that exercise stimulates hypertrophy, it is not yet well established if sustained exercise affects hyperplasia. Hyperplasia involves cellular division and is the process by which the total number of muscle cells is established (Johnston 1999). A study comparing muscle cellularity between farmed and wild sea bass suggested that the higher white muscle fiber density of wild fish (more hyperplasia) may have been determined by the higher exercise levels experienced by wild fish compared to those in a control setting (Periago et al. 2005). By exercising the fish in a controlled setting, scientists can better assess the muscle fiber growth patterns in teleost fish and how the muscle is changing in response to exercise (Palstra \& Planas, 2011).

In order for these phenotypic developments to take place, important biochemical changes must also occur. These biochemical changes in the skeletal muscle are activated in response to exercise and allow the exercised fish to develop a more aerobic phenotype than non-exercised fish (Palstra \& Planas, 2011). Exercise in fish is defined as an increase in the amount of contractile activity of the working muscle. During exercise, there is significant energy expenditure, and the skeletal muscle of the fish experiences an increase in fuel uptake and utilization (Palstra \& Planas, 2011). If fish develop higher aerobic capacity during bouts of sustained exercise, they will have increased output from the oxidative pathway and swimming becomes a more efficient process (Palstra \& Planas, 2011). 
McClelland (2012) performed an experiment demonstrating the biochemical advantage of swimming fish. In his research, he found that in red muscle, pyruvate dehydrogenase (PDH) is activated initially during exercise. PDH correlates with exercise intensity. As the fish were being exercised, levels of acetyl-CoA and acetyl-carnitine also increased, but free creatine decreased. These biochemical changes demonstrate that there is an increased rate of fatty acid oxidation in exercised fish. Increased oxidation allows the exercised fish to be more efficient swimmers (McClelland, 2012).

Researchers Brown et al. (2011) performed experiments to identify the energy expenditures in exercised yellowtail kingfish (Seriola lalandi). They found that the energy used for the exercised fish was much lower than the control group that was not exercised. Through constant exercise, the minimization of energy that results from swimming training allows the fish to devote more energy to growth and less to powering the swimming activity (Brown et al., 2011). This study, and many others, point to the understanding that continuous levels of exercise improve growth and swimming efficiency.

Researchers have conducted many studies on the exercised fish in an effort to determine the genetic activation that is contributing to a more efficient and aerobic phenotype. One gene that has been widely studied in species including pacu, carp, and zebrafish is MyoD (de Almeida et al., 2010; Johnston, 1998; Kobiyama et al., 1998; Weinberg et al., 1996). Interestingly, MyoD in these species is very similar in sequence to mammalian analogues. Within the gene, there is a highly conserved helix-loop-helix segment, which has a pivotal role in determination and differentiation of skeletal muscle (Kobiyama et al., 1998; Weintraub, 1991).

MyoD acts at multiple points in the skeletal muscle lineage to establish the skeletal muscle phenotype as shown in Fig. 1. (Kobiyama et al., 1998; Wang, 2015). During growth of 
the skeletal muscle, MyoD controls proliferating undifferentiated satellite cells and can cause increased myoblast proliferation and hyperplasia. However, it can also regulate myoblast differentiation and cause hypertrophy (de Almeida et al., 2010). Members of the MyoD gene

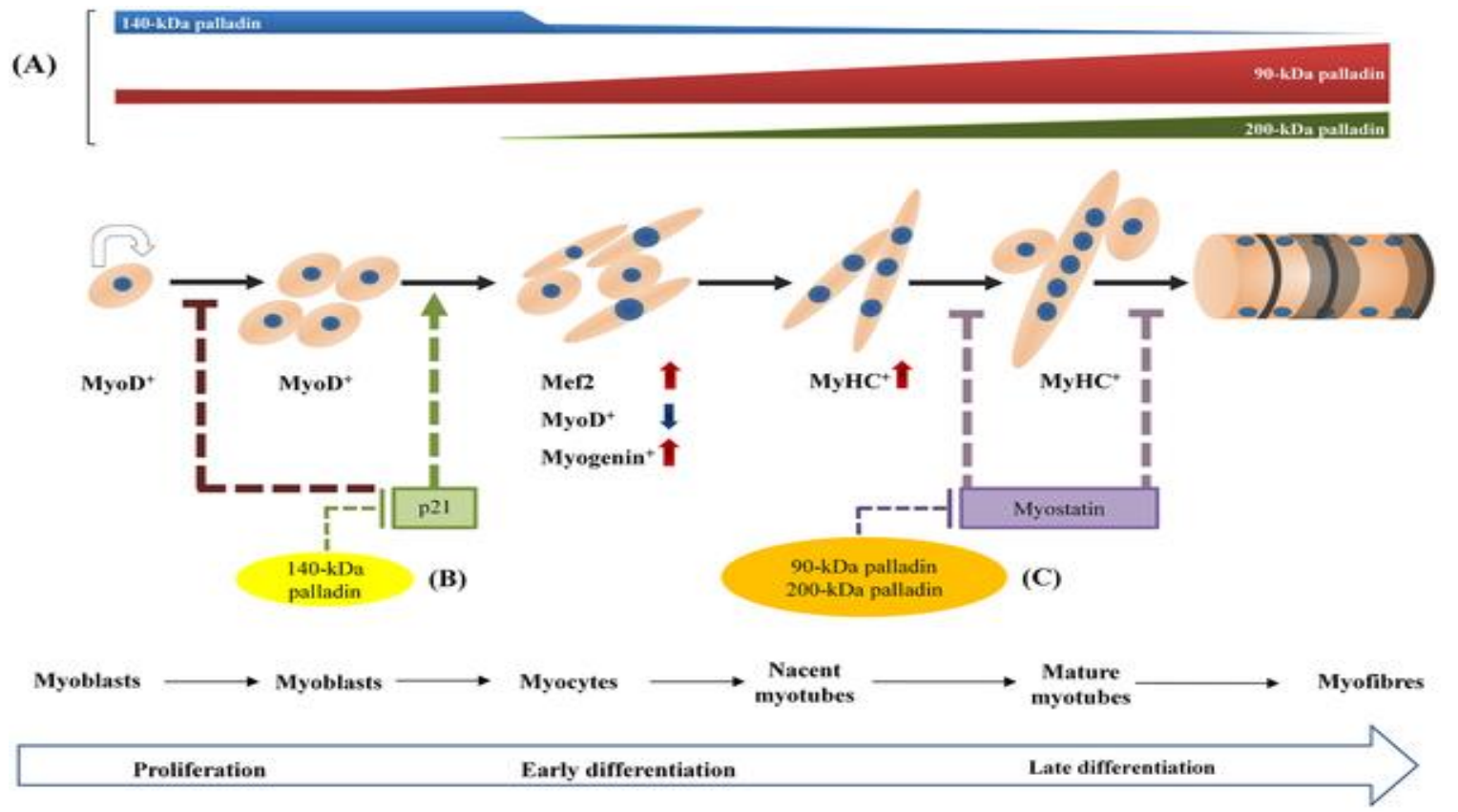

Fig. 1: Representation of MyoD cellular pathway. This protein is a myogenic factor that differentiates satellite cells into myofibres (Wang, 2015).

family auto-regulate their own expression and can activate other members to stabilize muscle differentiation ( $\mathrm{Li}, \mathrm{Li}, \&$ Olson, 1992). Within zebrafish, MyoD was detected as early as midgastrulation (Weinberg et al., 1996). Similarly, in carp MyoD was detected in embryos as early as 30-hours post-fertilization (Kobiyama et al., 1998). Continued measurements in the carp indicated that MyoD levels increased during development until hatching. Post-hatch, MyoD levels slowly decreased but there were still transcripts present in the fast muscle of 7 -month old juveniles (Kobiyama et al., 1998).

In pacu, de Almeida et al. (2010) found that MyoD was concentrated in fast fibers of the white muscle. They proposed that pacu muscular growth was associated with hyperplastic and 
hypertrophic growth (de Almeida et al., 2010). It is possible that MyoD is upregulated in response to exercise, as evidence by the increased hypertrophy and skeletal muscle development in exercised fish.

The benefits that result from constant exercise training are significant (Johnston, 1999). Growth will occur at higher levels if the fish are exposed to good conditions including oxygen levels, $\mathrm{pH}$ levels, temperature, and exercise at optimal swimming speed. It can thus be concluded that optimal exercise may have beneficial effects of major importance for the aquaculture industry (Johnston, 1999; Palstra \& Planas, 2011).

As noted above, many studies have shown that fish that have been exercised at optimal swimming speeds demonstrate a significant increase in body mass, body length, metabolic efficiency, and improved immune health (Palstra \& Planas, 2011). These trends have been examined across many species including $S$. dorsalis, which has been studied extensively by local researcher Laura Schwebel. Using samples of California yellowtail fish white muscle from her studies, I was able to analyze the muscle fiber patterning in response to exercise. More specifically, I was able to see if the increase in muscle mass of the exercised yellowtail was the result of larger white muscle fibers (hypertrophy) or recruitment of more fibers (hyperplasia). Finally, since samples were collected up to 6-months post-exercise, I was able to address whether or not muscle fibers are able to retain their exercise-induced patterning.

My research analyzes the physiology and development of California yellowtail (Seriola dorsalis) white muscle fibers in response to exercise. There are three main questions that I am addressing in my research: 1) Does time interval of exercise affect muscular patterning immediately post-exercise, 2) After a 6-month rest period, do the exercised fish have the same phenotype as displayed post-exercise, 3) Is MyoD upregulated in the exercised fish compared to 
the control and how does this expression change over time?

I studied three groups in order to address these questions. These included a control group, which was not exercised and maintained a "normal lifestyle", swimming freely at low flow speeds in a standardized control tank and two "raced" fish groups that were forced to swim at an optimal speed for 3-weeks and 4-weeks respectively in a custom designed raceway. Muscle tissue samples from members of each group were collected immediately following the period of exercise and for 6-months during the growout period.

To supplement my findings regarding the morphological changes of the white muscle fibers, I performed a genetic analysis, focusing on potential upregulation of MyoD. MyoD is a protein responsible for committing undifferentiated cells to becoming part of a muscle lineage. Due to its normal cellular function, I hypothesized that this would be one of many genes that would be upregulated and contribute to the large increase in muscle mass in exercised fish.

\section{Methods and Materials:}

\section{Experimental Subjects}

Aquaculture-reared California yellowtail transferred to the Southwest Fisheries Science Center in La Jolla, California 45-days after they were hatched. Fish recovered from the transfer and adjusted to the new environment for 1-week and then the exercise procedure was introduced and conducted by Schwebel (2016-17) under the SWFSC Institutional Animal Care and Use Committee approved protocol \#SW1602.

Exercise Protocol 
To address the first question regarding the effect of length of exercise on muscle fiber patterning (hypertrophy or hyperplasia), there were three groups that were compared. There were two groups that were exercised for different time periods and these were compared to a control group. The exercised groups swam constantly for a period of 3-weeks (3W) or 4-weeks (4W) and swam in a custom raceway (Figs. 2, 3) that was equipped with motors and pipes to control the flow speeds and water volume. In contrast the control group was kept in a separate control tank (Schwebel, 2017).
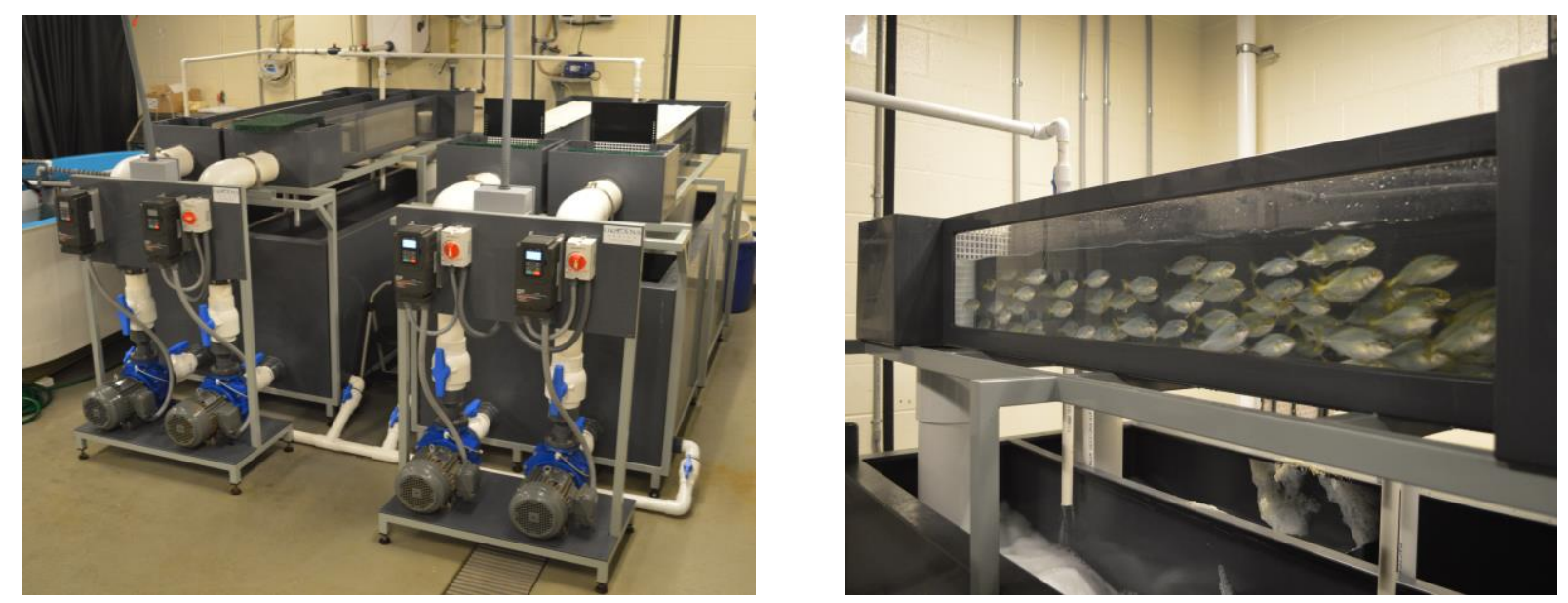

Figs. 2, 3: Two views of custom raceways designed to exercise the fish at optimal swimming speeds

The exercise groups were sorted into two different raceways each with 145 fish and the flow speed in each of the raceways started at less than $4 \mathrm{BL} / \mathrm{s}$ and then slowly increased to $61.6 \pm$ $3.2 \mathrm{~cm} / \mathrm{s}(8.7 \mathrm{BL} / \mathrm{s})$. This speed was calculated based on cost of transport and the optimal swimming speed, which was studied by Palstra et al. (2015) on the yellowtail kingfish. Flow speed was checked each day and was adjusted to maintain the optimal speed of the fish depending on body length and growth. The fish were fed 5-7 times a day during the exercise protocol. 


\section{Growout Period}

Once the exercise was complete for the $3 \mathrm{~W}$ and $4 \mathrm{~W}$ groups, the fish were transferred to a growout tank (Fig. 4) for 6-months. The water temperature in the growout tank was $22.1 \pm 0.3^{\circ} \mathrm{C}$ and other important experimental conditions including oxygen levels and water quality were constantly monitored. Water was supplied to the tanks at a rate of $23 \mathrm{~L} / \mathrm{min}$ and the fish in these tanks were fed 3-5 times a day for 6-days each week.

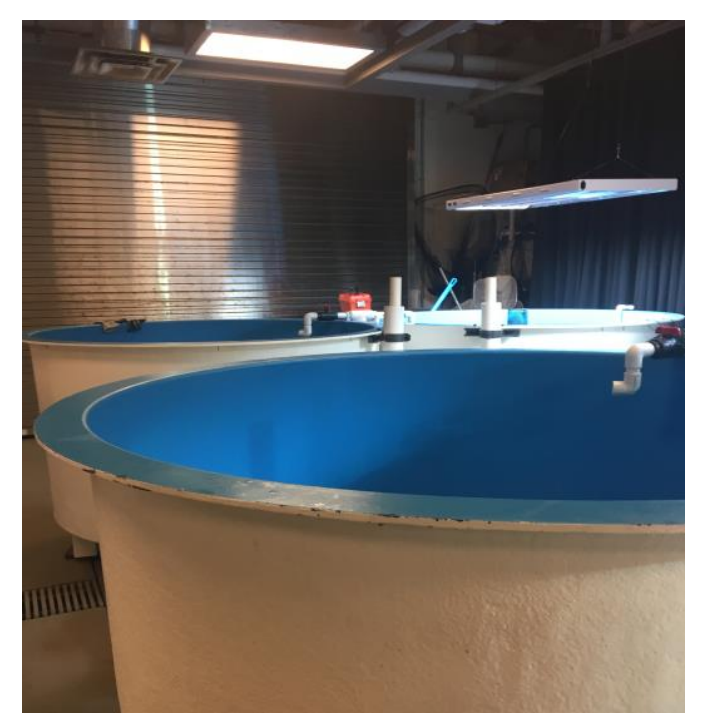

Fig. 4: Growout tanks used to contain fish post-exercise.

Fiber Analysis

In order to analyze the white muscle fiber patterns of the yellowtail, white muscle samples were excised from 4 different fish within in each experimental group. These muscle samples were fixed in formalin, sectioned, and subsequently stained. They were then placed on microscope slides for image analysis (Fig. 5). Using the collected images, muscle fiber analysis was performed using a computer program called ImageJ. This program allowed measurements to be made to determine the area and roundness of thousands of individual white muscle fibers. In 
order to best identify fiber trends in each group, 60 fiber measurements were made from the 4 different fish, yielding a total of 240 measurements for the control, the 3-week exercise, and 4week exercise groups. Any fibers that were not above a roundness value of 0.5 , indicating that the muscle fibers were irregularly shaped, were excluded from the measurements. This protocol was performed with monthly samples from the 3 groups until the experiment was terminated after 6-months.

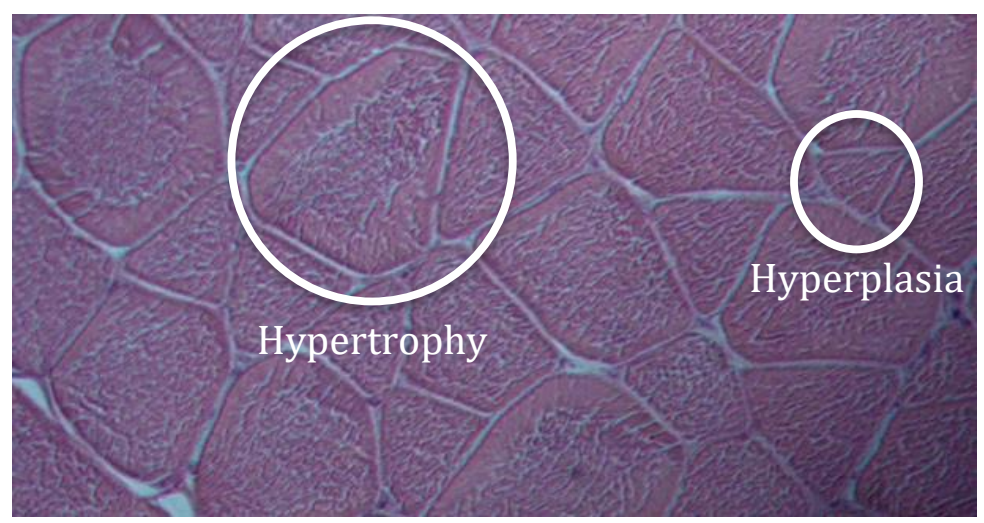

Fig. 5: Microscope slide of white muscle and individual muscle fibers. Fibers demonstrating hypertrophy $(7000+$ $\left.\mu \mathrm{m}^{2}\right)$ and hyperplasia $\left(0-1000 \mu \mathrm{m}^{2}\right)$ are indicated above.

Using the data collected from the muscle fiber measurements, fibers were classified as hypertrophic, hyperplastic, or normal according to their respective sizes. Graphs were constructed to determine whether or not each group of fish was undergoing hypertrophy or hyperplasia. With these graphs, trend in the pattern of white muscle fibers over a 6-month period could be analyzed and compared between the three groups.

\section{Western Blot}

After this data was collected, the Western Blot protocol was instituted for genetic analysis. In order to test the levels of MyoD that were in the fish muscle, small samples of the frozen yellowtail white muscle were collected, weighed, and homogenized into solution with 
10mM Tris buffer $\mathrm{pH}$ 7.5. After making homogenized solutions, a Bradford assay was performed to determine the relative protein concentration in each of the samples. Before the SDS-PAGE analysis was run, the samples were standardized so that an equal amount of protein would be loaded into each well. Once all samples had the same amount of protein, the gel was loaded and the proteins were allowed to separate via electrophoresis. After the proteins were separated on a gel, the proteins in each sample were transferred to a PVDF-membrane. Once the proteins bound to the membrane, immunodetection was performed to allow analysis of MyoD concentration in each of the white muscle samples.

\section{Immunodetection}

The process of protein detection on the membrane is called immunodetection. In order to locate MyoD, a primary antibody, MyoD Antibody (1:200) rabbit polyclonal IgG, is added to the membrane that binds to the protein. After the primary antibody has been bound to MyoD, a secondary antibody, goat anti-rabbit IgG alkaline-phosphatase conjugated (1:10000), is applied. The secondary antibody binds to the primary antibody to make the MyoD appear as distinct bands on the membrane. The GelDoc can quantitatively determine density of the bands produced by the MyoD. Based on relative densities, we can determine if more MyoD expressed in the control or exercise group.

\section{Results:}

\section{Raceway Experiment}

Comparing the $3 \mathrm{~W}, 4 \mathrm{~W}$, and control groups, immediately following the racing procedure, the $3 \mathrm{~W}$ demonstrated a $15 \%$ increase in growth compared to the control group and the $4 \mathrm{~W}$ group demonstrated a 38\% increase in growth (Schwebel, 2017). Looking at the distribution of muscle 
fiber areas (Fig. 6), it is clear that the control group had the most small fibers out of the three groups. The normal distribution of fibers sizes for the control group is shifted toward the left of the graph, with the lowest mode of the three groups $\left(2000-2500 \mu \mathrm{m}^{2}\right)$.

The $3 \mathrm{~W}$ and $4 \mathrm{~W}$ groups tend to have distributions shifted to the right, representing a higher frequency of hypertrophic fibers (arbitrarily classified as fibers $7000+\mu \mathrm{m}^{2}$ ) than the control group. In order to see the distribution of hypertrophic fibers in the exercised groups more

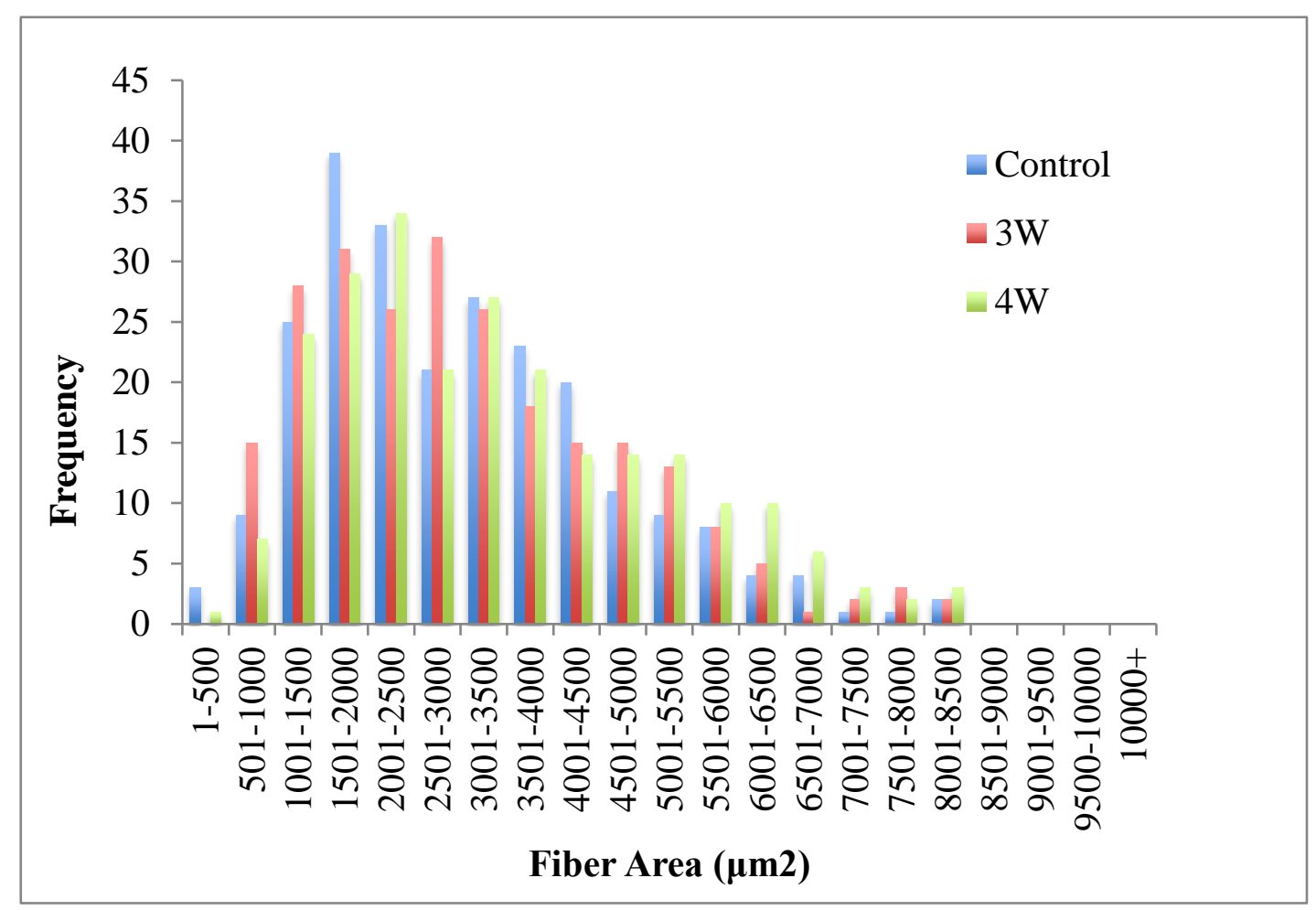

Fig. 6: Histogram representing distribution of white muscle fiber areas $\left(\mu \mathrm{m}^{2}\right)$ after the completion of the exercise period. Distribution shows that the control group had the highest frequency of small fibers, and bother exercise groups had a greater amount of large fibers (hypertrophy).

clearly, bin sizes of fiber area are increased in Fig. 7. From this histogram (Fig .7), it is clear that the $4 \mathrm{~W}$ group had the highest frequency of hypertrophic fibers. This supports previous research, with trout, zebrafish, and yellowtail, indicating that exercise induces hypertrophy (Bugeon, Lefevre, \& Fauconneau, 2004; Davison 1997; Johnston 1999; Johnston et al., 2011; Johnston and 
Moon 1980). The 4W group had the highest frequency of fibers in the third bin (5001-7000 $\mu \mathrm{m}^{2}$ ). Though the $3 \mathrm{~W}$ and $4 \mathrm{~W}$ groups had an increased frequency of large fibers when compared to the control, the $4 \mathrm{~W}$ had the greatest difference.

From these histograms (Figs. $6 \& 7$ ) it is evident that exercise stimulates hypertrophy in the exercised California yellowtail. However, the results also indicate that longer periods of exercise are able to stimulate more hypertrophy than shorter periods of exercise. The $23 \%$ increase in growth when comparing the $3 \mathrm{~W}$ to the $4 \mathrm{~W}$ fish can be attributed to an increase in

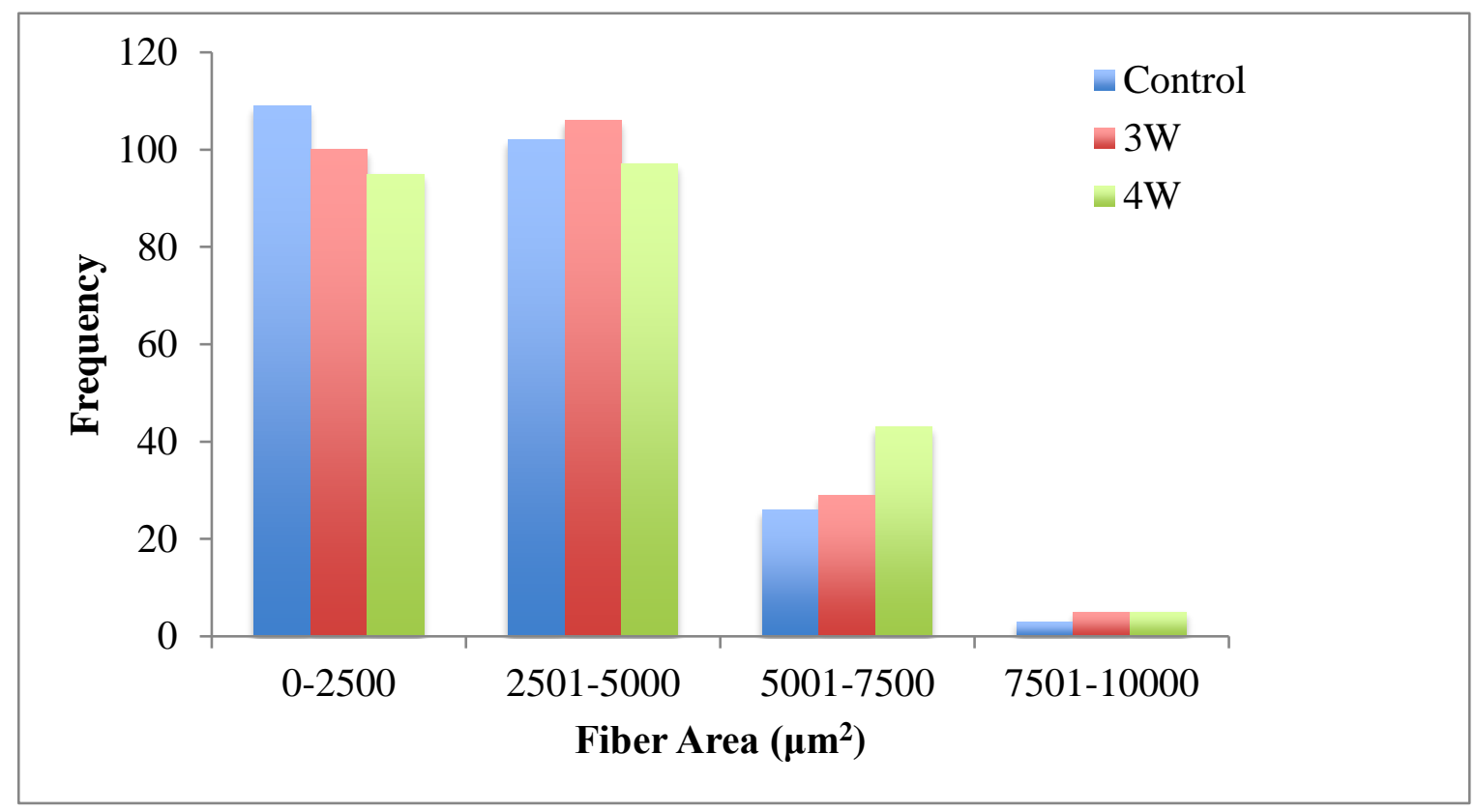

Fig. 7: Histogram representing condensed distribution of white muscle fiber areas $\left(\mu \mathrm{m}^{2}\right)$ of the three groups immediately post-exercise. The fish that have been raced longer have developed larger muscle fibers.

hypertrophy of the $4 \mathrm{~W}$ fish. Comparing the mean fiber area in the three groups immediately post-exercise, there is a significant difference in the mean fiber area of the $4 \mathrm{~W}$ group (3365.5 \pm $113.5 \mu \mathrm{m}^{2}$ ). The control and 3W group had fiber sizes $3034.8 \pm 103 \mu \mathrm{m}^{2}$ and $3091.2 \pm 106.9$ 
$\mu \mathrm{m}^{2}$ respectively (Fig. 8). Though there was a slight increase in the mean fiber size of the $3 \mathrm{~W}$ group compared to the control, this was not significantly different.

After the raceway procedure, it is evident that exercise at $U_{\text {opt }}$ stimulates hypertrophy in the California yellowtail. More hypertrophy and total body growth compared to the control is also more evident in the fish that are exercised for longer periods of time.

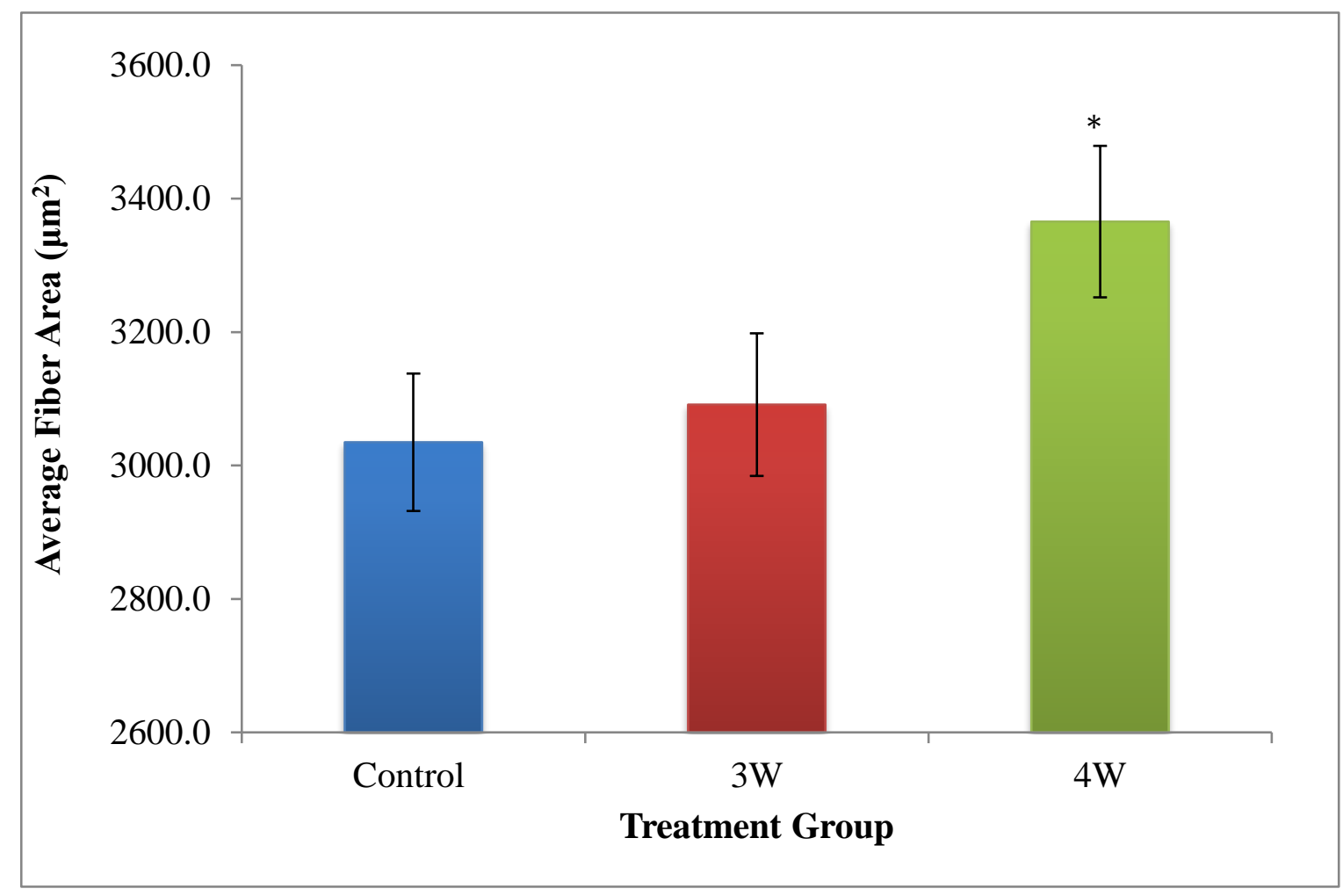

Fig. 8: Barplot represents mean fiber area $\left(\mu \mathrm{m}^{2}\right)$ of each experimental group postexercise and error bars indicating $\pm 1 \mathrm{STE}$. There was a significant difference of mean fiber area between $4 \mathrm{~W}$ and the other groups.

\section{Growout Experiment}

After a 6-month growout period, following a continuous period of exercise training, the control group had developed a very distinct muscular phenotype compared to the two exercise groups. The mosaic plot (Fig. 9) below shows a comparison between fiber sizes of the white muscle of the three groups immediately following exercise and at the end of the growout period. 
The small fibers in pale blue are categorized as those fibers demonstrating hyperplasia (0$\left.1000 \mu \mathrm{m}^{2}\right)$, medium fibers baby blue (1000-7000 $\left.\mu \mathrm{m}^{2}\right)$, and finally the largest hypertrophic fibers in dark blue $\left(7000+\mu \mathrm{m}^{2}\right)$. The first three columns on the left represent the groups immediately post-exercise. The control group had the smallest amount of hypertrophic fibers as seen above in the histogram (Fig.6) and the $3 \mathrm{~W}$ groups demonstrate the most hyperplasia.

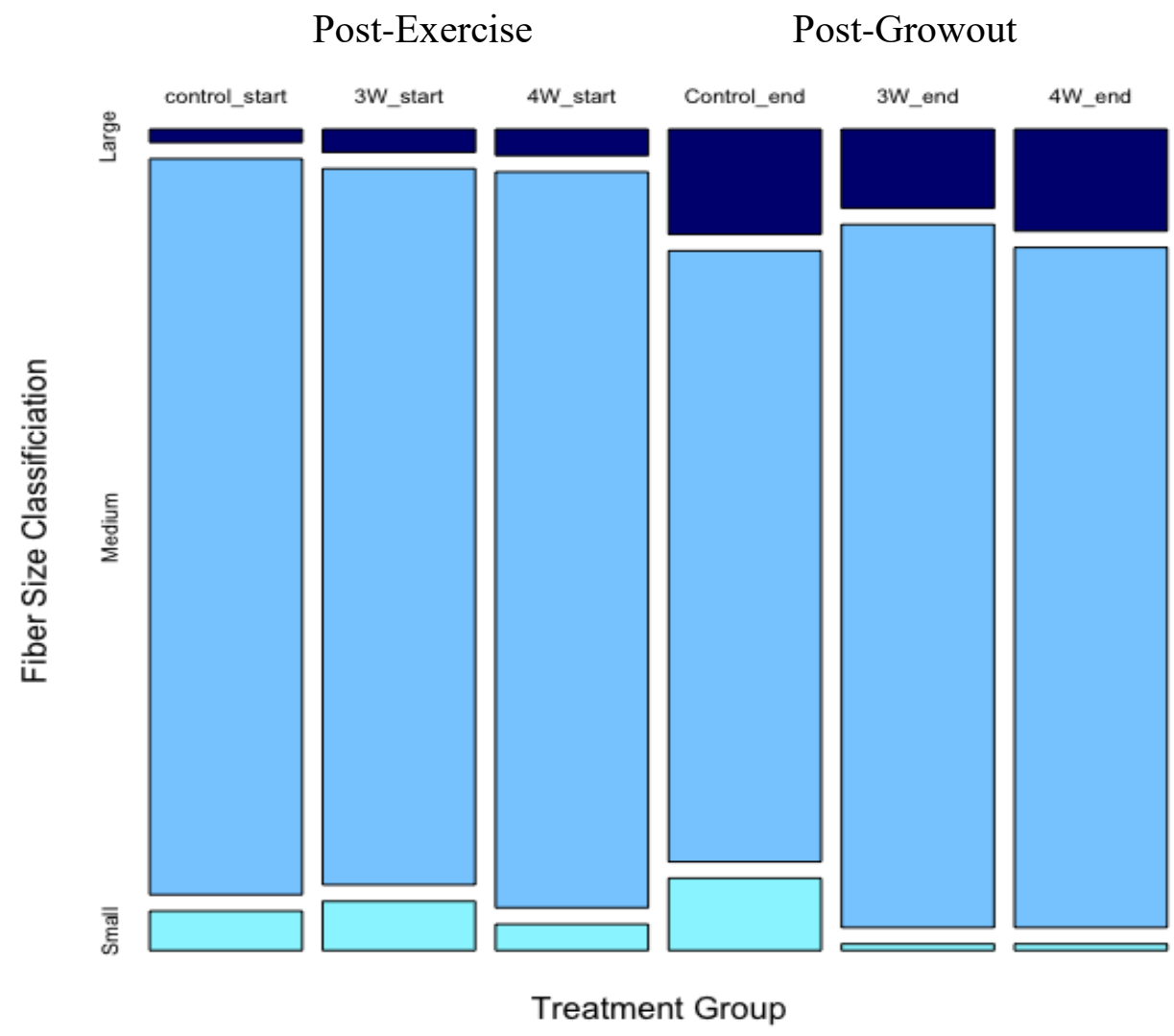

Fig. 9: Mosaic plot representing the distribution of white muscle fibers in each of the experimental groups. The data compares the fiber distribution immediately post-exercise and post-growout. The fibers are classified as small $\left(0-1000 \mu \mathrm{m}^{2}\right)$ indicating hyperplasia, medium $\left(1000-7000 \mu \mathrm{m}^{2}\right)$, and large $\left(7000+\mu \mathrm{m}^{2}\right)$ indicating hypertrophy.

However, looking at the last three columns (Fig. 9), which represent the end of the growout procedure, all three groups have a higher percentage of hypertrophic (large) fibers. The control group had the highest proportion of large fibers compared to the exercise groups by the 
end of the growout, which is opposite the result seen after the exercise procedure. The control group also had a much higher proportion of small fibers, exhibiting the greatest amount of hyperplasia. Interestingly, the proportions of large and small fibers were comparable between the $3 \mathrm{~W}$ and $4 \mathrm{~W}$ groups at the end of the growout period.

Taking a closer look at the trend of hyperplasia in each of these groups over the 6-month growout period, it appears that exercise has actually downregulated fiber recruitment in the $3 \mathrm{~W}$ and $4 \mathrm{~W}$ groups compared to the control (Fig. 10). Over the 6-months, both exercise groups show a steady decrease in the recruitment of small fibers (Fig. 10). In contrast, the control has greater hyperplasia at the end of the growout period but there is not a clear trend in recruitment of small fibers. It is clear that the control group has a much greater accumulation of small fibers over the growout period than both of the exercised groups.

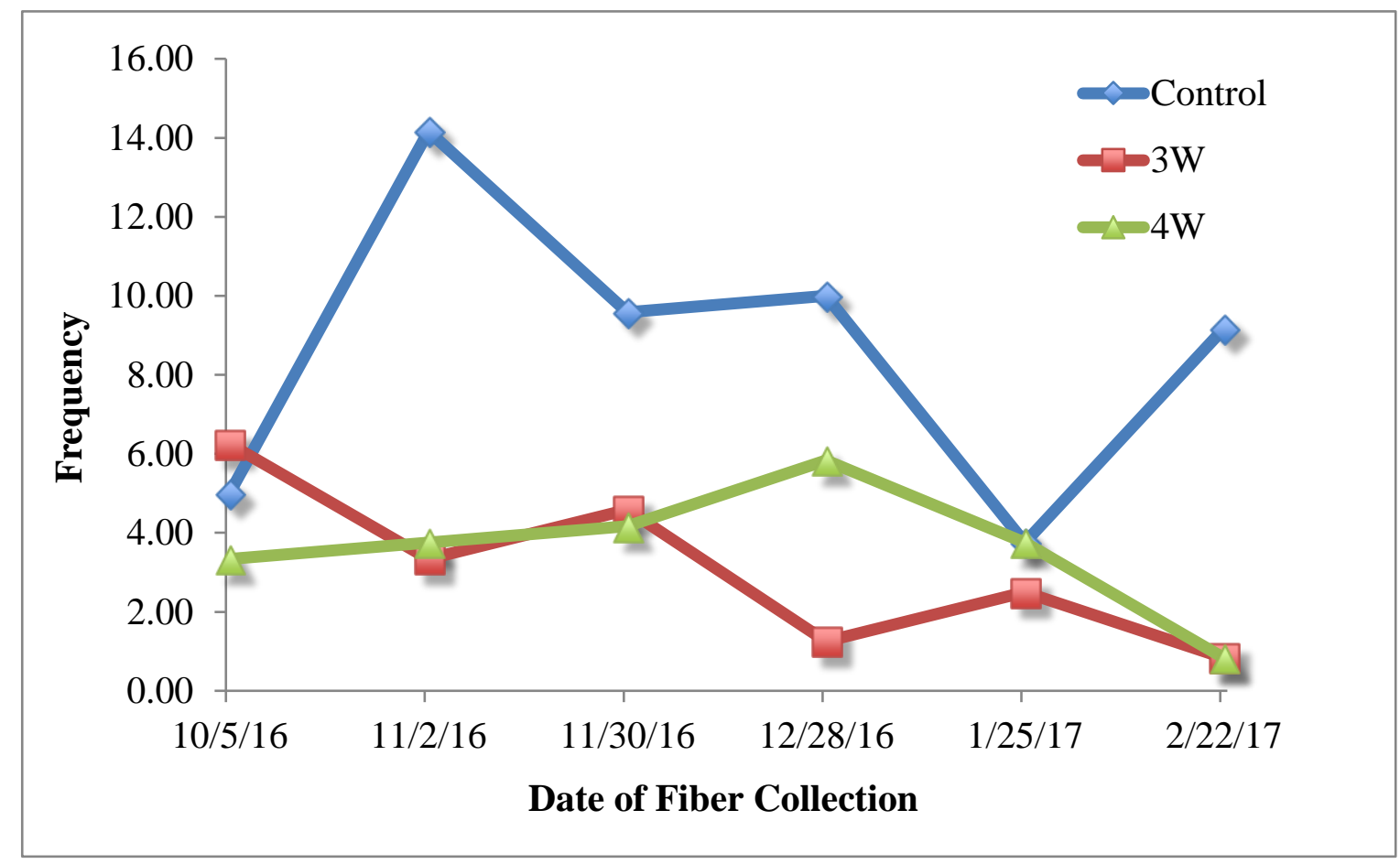

Fig. 10: Line graph represents hyperplasia (fibers $0-1000 \mu \mathrm{m}^{2}$ ) over the growout period. There is a steady decrease of hyperplasia in both exercise groups and no clear pattern of fiber recruitment in the control. 
Taking a look at the occurrence of hypertrophy during the 6-month growout period (Fig. 11), it is supported that hypertrophy is a natural process and that enlargement of fibers will occur as with age. All three groups demonstrated an increase in the amount of hypertrophy during the growout period (Fig. 11). Both of the exercise groups did have a slight increase in hypertrophy compared to the control group at the start of this period, but this is likely the result of the exercise procedure. At the end of the 6-months, all three groups had a similar amount of hypertrophy in the white muscle.

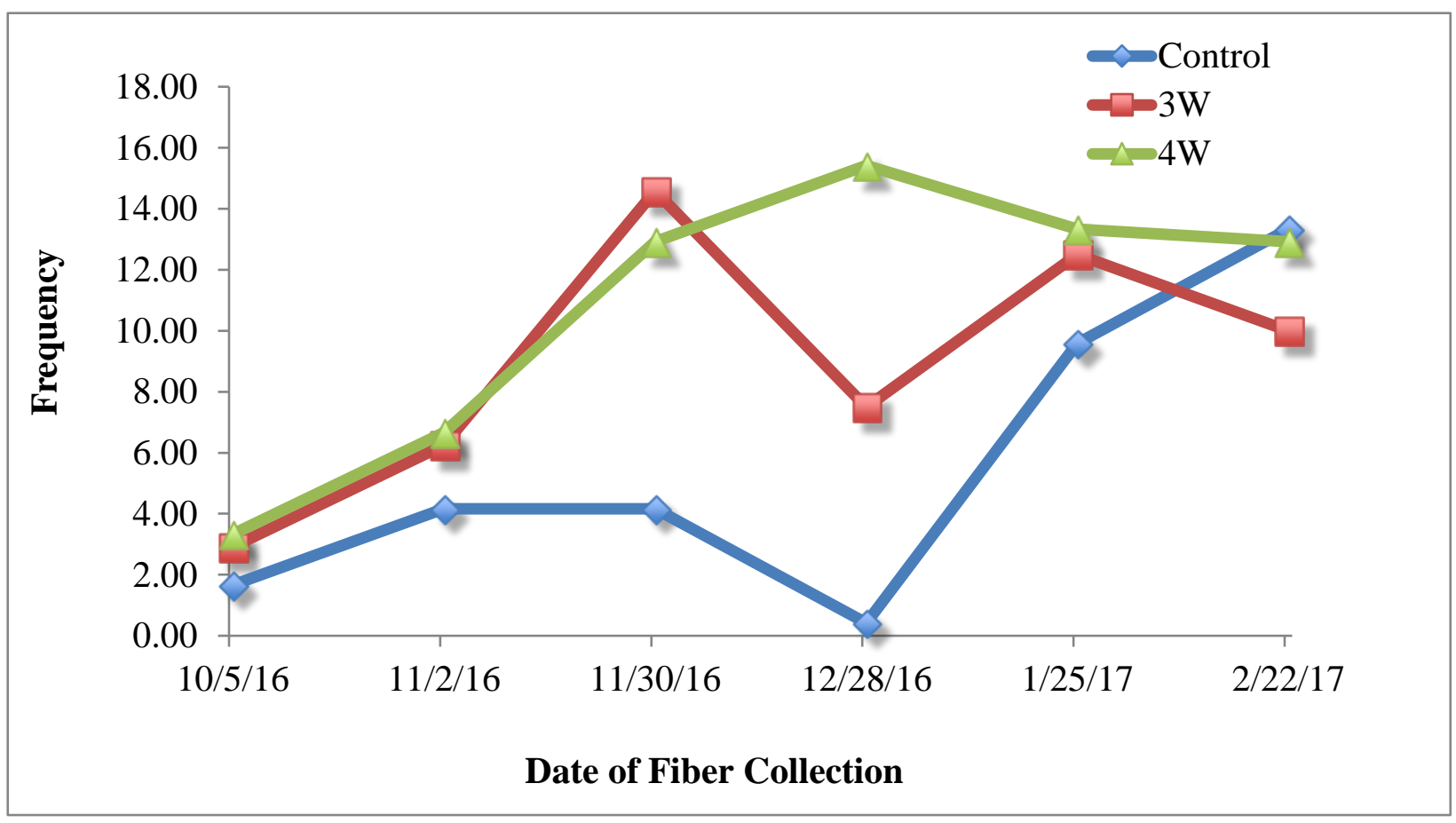

Fig. 11: Line graph represents the trend of hypertrophy (fibers $7000+\mu \mathrm{m}^{2}$ ) over the 6-month growout period. There is a steady increase in the trend of increasing fiber size in all three groups.

Comparing the mean fiber areas of the three experimental groups at the end of the growout period showed that the effect of exercise did not last. At the end of the 6-months, the control, 3W, and 4W groups had similar mean white muscle fiber areas $\left(4121.4 \pm 160.6 \mu \mathrm{m}^{2}\right.$, 
$4046.1 \pm 134.3 \mu \mathrm{m}^{2}$, and $4249.4 \pm 149.2 \mu \mathrm{m}^{2}$ ). Schwebel (2017) also found no significant difference in the mass of these three groups at the end of the growout period. Exercise did significantly impact the mass of the fish immediately post-exercise, however this trend did not persist and by the end of the experiment the fish were all similar in total mass.

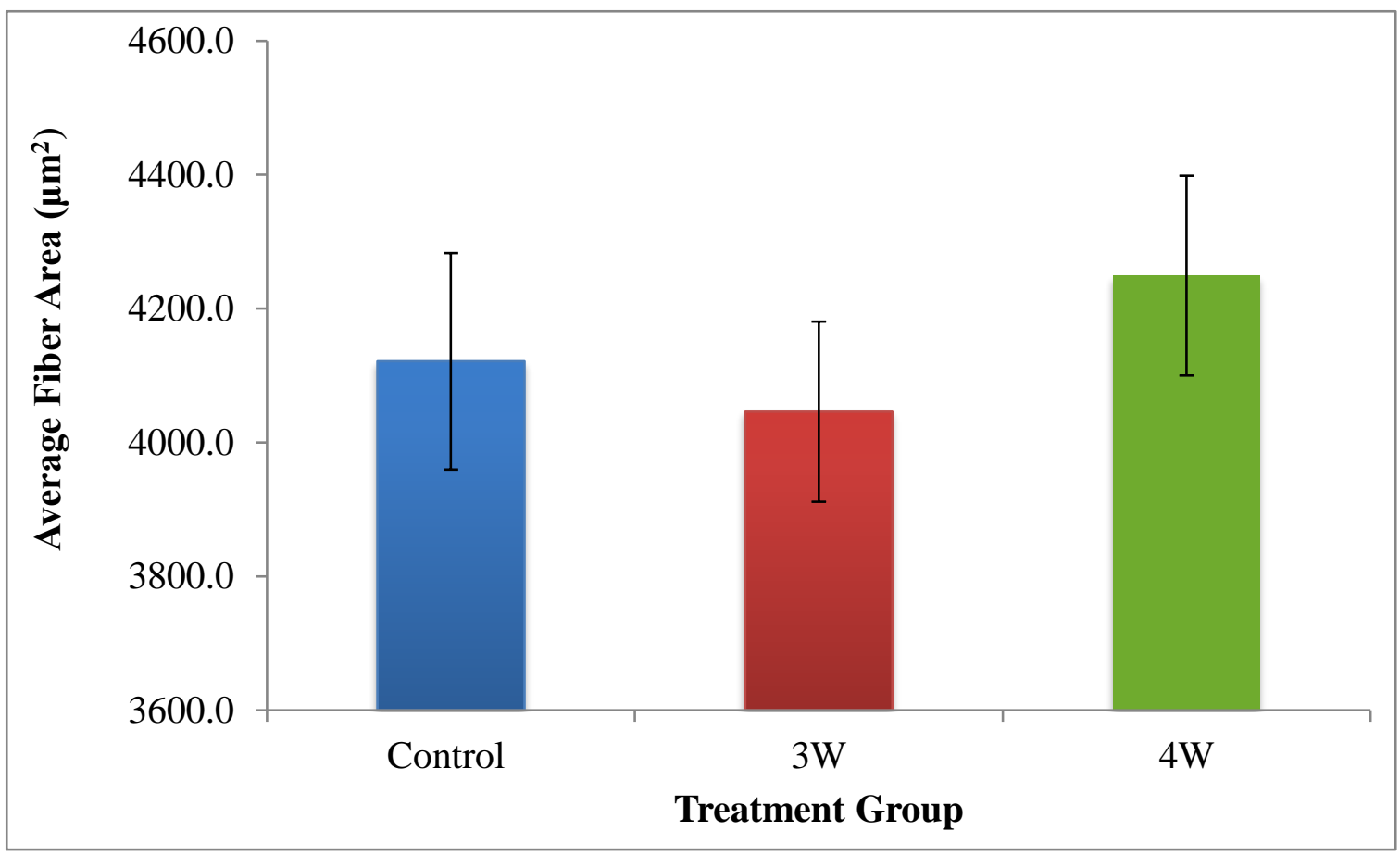

Fig. 12: Barplot represents mean fiber area $\left(\mu \mathrm{m}^{2}\right)$ of each experimental group postexercise and error bars indicating \pm 1 STE. There was no significant difference of mean fiber area between and of the groups.

Since the mean fiber area was not significantly different, it was not unexpected to find that there was no significant difference in the total body mass between these three groups of fish.

\section{Western Blot and Immunodetection}

Looking at the regulation of $\mathrm{MyoD}$ in the exercised and control samples, it is clear that MyoD is upregulated in the exercise groups (RW) compared to the control (C). MyoD is represented by the bottom bands on the membrane below (Fig. 13). There is a gradient of band 
density from the start of the experiment to the end of the experiment. At the start of the raceway experiment (8/24) the level of MyoD is the highest in both the exercise and control groups, shown by the darker bands. The density of $\mathrm{MyoD}$ is also higher in the exercise groups at all points of collection except for the $9 / 5$ collection date.

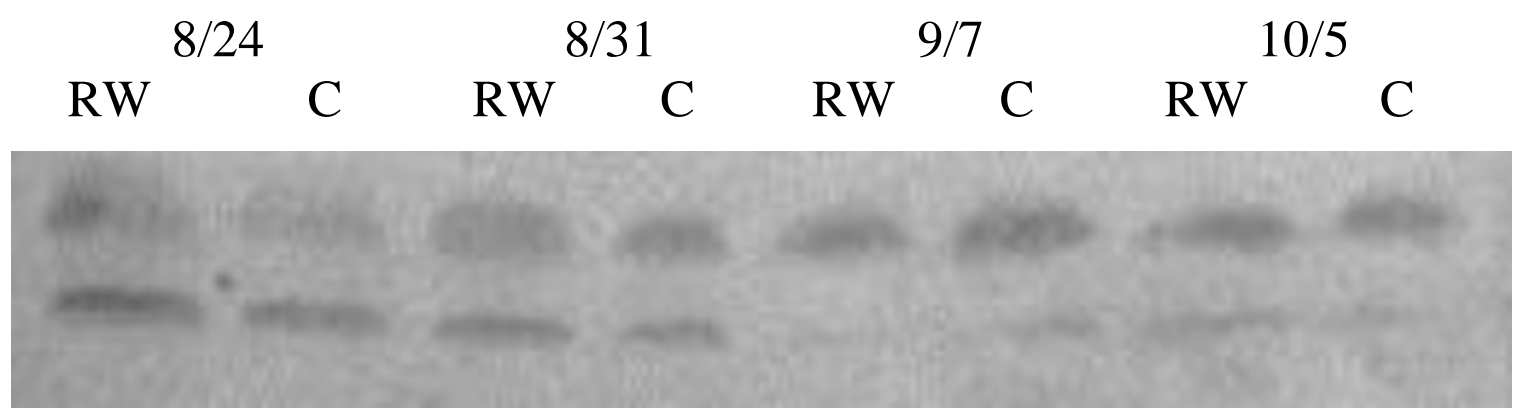

Fig. 13: Western Blot of MyoD. The bands get fainter as the time continues and the most dense band is seen at the start of the exercise procedure in the RW 8/24 sample.

The GelDoc validates the upregulation of $\mathrm{MyoD}$ in the exercise groups compared to the control group (except at 9/5) by quantifying the band densities in each sample. The line graph (Fig. 14) shows the relative densities of $\mathrm{MyoD}$ in the samples at the four collection dates.

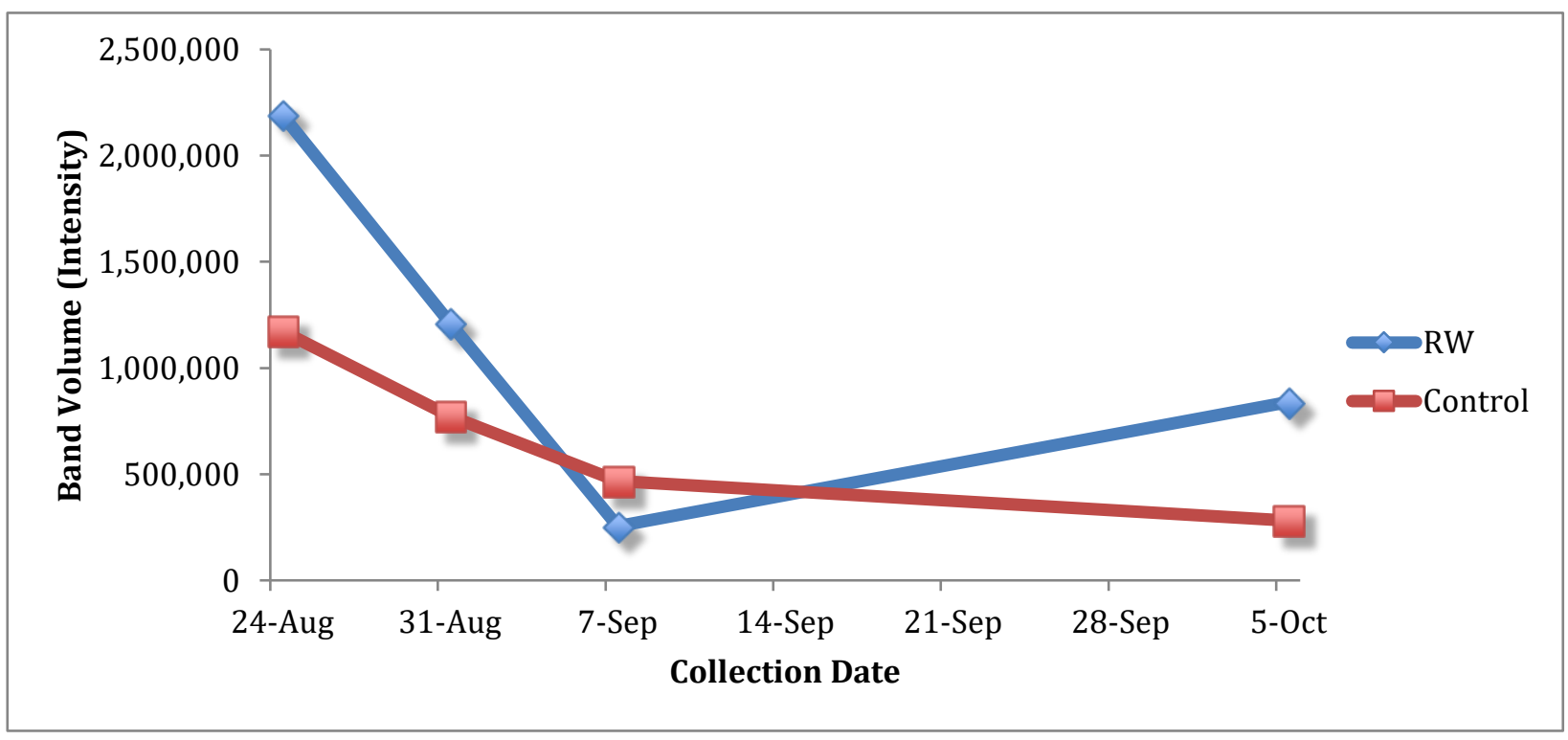

Fig. 14: Line graph represents relative band densities of MyoD in each the white muscle samples at various collection dates. The start of the raceway experiment was on 8/24/16. 


\section{Discussion:}

This research has opened a variety of doors for future research opportunities with exercise training in fish. While working on this project, I learned a lot about the importance of aquaculture and the benefits of conducting this kind of research. Aquaculture is a rapidly growing industry and in 2016, the per capita fish consumption was higher than ever reaching over 20kg/year (Food an Agriculture Organization of the United Nations, 2018). Further research on individual fish species is necessary in order to best serve the aquaculture industry and to provide food for a growing population.

From this project, it was really interesting to learn that the length of exercise did significantly affect the muscle patterning in the California yellowtail and also had a significant effect on total growth. It would be interesting to conduct further exercise studies under the same protocol, but increasing the length of exercise. With a nearly $23 \%$ increase in body mass from 3weeks to 4-weeks, an increase from 4 to 5-weeks could have an even greater effect on the body mass of the exercised fish.

This research also showed that over time, fish white muscle naturally tends to demonstrate hypertrophy and hyperplasia as evidenced by the control group during the growout period. Interestingly however, when the exercised groups were taken out of the "exercise state" they had a steady decline in hyperplasia. Nonetheless, as a result of exercise, they had a more rapid development of hypertrophy and greater increase in mass than the control group.

Finally, in addition to raceway analyses, genetic analyses should continue in order to best determine what is causing these changes in the white muscular patterning. More Western Blots can help us understand the role of $\mathrm{MyoD}$ during exercise, and also allow us to determine exactly how much it can be upregulated in response to exercise. Another gene of interest that should be 
studied is HIF1 $\alpha$. This is also known as hypoxia-inducible factor and acts in part of the signaling pathway to promote angiogenesis. Angiogenesis increases the vascularization of fast muscle during exercise training (Palstra et al., 2014). Recent studies have also shown that swimming zebrafish demonstrate increased expression of HIF in the fast muscle of the larval stages (Palstra, 2014). If these and other genes are upregulated by exercise and are contributing to muscle patterning, further research could help determine how to optimize the exercise protocol to reach maximal expression of these genes.

Similar experiments would be very useful to implement in the aquaculture industry. If we are able to grow larger and healthier fish by instituting an exercise regime, we could have a more secure and stable method to feed a growing population. 


\section{Works Cited}

“A Study of The Yellowtail Seriola dorsalis (Gill)." Calisphere, The Regents of the University of California, 2011, content.cdlib.org/vdocId=kt15800182;NAAN=13030\&doc. view=frames\&chunk.id=d0e117\&toc $\cdot$ depth=1\&toc.id=\&brand=calisphere.

Brown, E. J., Bruce, M., Pether, S., \& Herbert, N. A. (2011). Do swimming fish always grow fast? Investigating the magnitude and physiological basis of exercise-induced growth in juvenile New Zealand yellowtail kingfish, Seriola lalandi Fish Physiol Biochem, 37(2), 327-336. doi:10.1007/s10695-011-9500-5

Bugeon J, Lefevre F and Fauconneau B 2004. Correlated changes in skeletal muscle connective tissue and flesh texture during starvation and re-feeding in brown trout (Salmo trutta) reared in seawater. Journal of the Science of Food and Agriculture 84, 1433-1441.

Campinho MA, Sweeney GE and Power DM 2006. Regulation of troponin T expression during muscle development in sea bream (Sparus auratus Linnaeus): the potential role of thyroid hormones. Journal of Experimental Biology 209, 4751-4767.

Carpene` E, Veggetti A and Mascarello F 1982. Histochemical fibre types in the lateral muscle of fishes in fresh, brackish and salt water. Journal of Fish Biology 20, 379-396.

Davison, W. (1997). The Effects of Exercise Training on Teleost Fish, a Review of Recent Literature. Comparative Biochemistry and Physiology Part A: Physiology, 117(1), 67-75. doi:http://dx.doi.org/10.1016/S0300-9629(96)00284-8

De Almeida, Fernanda Losi Alves, et al. "Quantitative expression of myogenic regulatory factors MyoD and myogenin in pacu (Piaractus mesopotamicus) skeletal muscle during growth." Micron 41.8 (2010): 997-1004. 
Fauconneau B, Andre S, Chmaitilly J, Le Bail P-Y, Krieg F and Kaushik SJ 1997. Control of skeletal muscle fibres and adipose cells size in the flesh of rainbow trout. Journal of Fish Biology 50, 296-314.

Froehlich, J. M., Fowler, Z. G., Galt, N. J., Smith, D. L., \& Biga, P. R. (2013). Sarcopenia and piscines: The case for indeterminate-growing fish as unique genetic model organisms in aging and longevity research. Frontiers in Genetics, 4(AUG), 1-8. http://doi.org/10.3389/fgene.2013.00159

Garcia-Alcazar A, Ros G, Gil F (2005) Muscle cellularity and flesh quality of wild and farmed sea bass, Dicentrarchuslabrax. Aquaculture 249:175-188

"Global per Capita Fish Consumption Rises above 20 Kilograms a Year." Fao.org, FAO of the UN, 7 July 2016, www.fao.org/news/story/en/item/421871/icode/.

Johnston, Ian A. "Muscle development and growth: potential implications for flesh quality in fish." Aquaculture 177.1-4 (1999): 99-115.

Johnston, I. a, Bower, N. I., \& Macqueen, D. J. (2011). Growth and the regulation of myotomal muscle mass in teleost fish. The Journal of Experimental Biology, 214(Pt 10), 16171628. http://doi.org/10.1242/jeb.038620

Johnston IA, Moon TW. Exercise training in skeletal muscle of brook trout (Salvelinus fontinalis). J. Exp. Biol. 1980; 87:177Y94.

Kiessling A, Johansson L and Kiessling KH 1990. Effects of starvation on rainbow trout muscle. Acta Agriculturae Scandinavica 40, 309-324.

Kiessling, Anders, Kari Ruohonen, and Marit Bjørnevik. "Muscle fibre growth and quality in fish." (2006). 
Kobiyama, Atsushi, et al. "Molecular cloning and developmental expression patterns of the MyoD and MEF2 families of muscle transcription factors in the carp." Journal of experimental biology 201.20 (1998): 2801-2813.

Li, Li, and Eric N. Olson. "Regulation of muscle cell growth and differentiation by the MyoD family of helix-loop-helix proteins." Advances in cancer research. Vol. 58. Academic Press, 1992. 95-119.

Martin, C. I., and I. A. Johnston. "Endurance exercise training in common carp Cyprinus carpio L. induces proliferation of myonuclei in fast muscle fibres and slow muscle fibre hypertrophy." Journal of fish biology 69.4 (2006): 1221-1227.

McClelland, Grant B. "Muscle remodeling and the exercise physiology of fish." Exercise and sport sciences reviews 40.3 (2012): 165-173.

Nakada, M. (2008). Capture-based aquaculture of yellowtail. Retrieved from Rome: http://www.fao.org/3/a-i0254e/i0254e10.pdf

NOAA. “Aquaculture.” NOAA Fisheries, www.fisheries.noaa.gov/topic/aqculture .

Palstra, Arjan P., and Josep V. Planas. "Fish under exercise." Fish Physiology and Biochemistry 37.2 (2011): 259-272.

Palstra, Arjan P., et al. "Establishing zebrafish as a novel exercise model: swimming economy, swimming-enhanced growth and muscle growth marker gene expression." PLoS One 5.12 (2010): e14483.

Palstra, Arjan P., et al. "Forced sustained swimming exercise at optimal speed enhances growth of juvenile yellowtail kingfish (Seriola lalandi)." Frontiers in physiology 5 (2015): 506.

Palstra, A. P., Rovira, M., Rizo-Roca, D., Torrella, J. R., Spaink, H. P., \& Planas, J. V. (2014). Swimming-induced exercise promotes hypertrophy and vascularization of fast skeletal 
muscle fibres and activation of myogenic and angiogenic transcriptional programs in adult zebrafish. BMC Genomics 2014, 15(1136), 1-20. http://doi.org/10.1186/1471-2164$15-1136$

Periago, Ma J., et al. "Muscle cellularity and flesh quality of wild and farmed sea bass, Dicentrarchus labrax L." Aquaculture 249.1-4 (2005): 175-188.

Rehfeldt, C., et al. "Advances in research on the prenatal development of skeletal muscle in animals in relation to the quality of muscle-based food. I. Regulation of myogenesis and environmental impact." Animal 5.5 (2011): 703-717.

Rescan PY 2008. New insights into skeletal muscle development and growth in teleost fishes. Journal of Experimental Zoology 310, 541-548.

Rowlerson A and Veggetti A 2001. Cellular mechanisms of post-embryonic muscle growth in aquaculture species. In Muscle development and growth. Fish physiology series, vol. 18. (ed. IA Johnston), pp. 103-140. Academic Press, San Diego, CA, USA.

Silva P, Valente LMP, Olmedo M, Galante MH, Monteiro RAF and Rocha E 2009a. Hyperplastic and hypertrophic growth of lateral muscle in blackspot seabream Pagellus bogaraveo from hatching to juvenile. Journal of Fish Biology 74, 37-53.

Stickland NC 1983. Growth and development of muscle fibres in the rainbow trout (Salmo gaidneri). Journal of Anatomy 137, 323-333.

Schwebel, L (2017) M.S. Thesis. University of San Diego, http://digital.sandiego.edu/theses/23.

Wang, Hao-Ven. "Dual roles of palladin protein in in vitro myogenesis: inhibition of early induction but promotion of myotube maturation." PloS one 10.4 (2015): e0124762. 
Wegner, N. C., Drawbridge, M. A., \& Hyde, J. R. (in review). Reduced swimming and metabolic fitness of aquaculture-reared California Yellowtail (Seriola dorsalis) in comparison to wild-caught fish. Aquaculture.

Weatherley AH and Gill HS 1987. The biology of fish growth. Academic Press, London, UK. Weatherley AH, Gill HS and Lobo AF 1988. Recruitment and maximal diameter of axial muscle fibres in teleosts and their relationship to somatic growth and ultimate size. Journal of Fish Biology 33, 851-859.

Weinberg, E. S., Allende, M. L., Kelly, C. S., Abdelhamid, A., Murakami, T., Andermann, P., Doerre, G., Grunwald, D. and Riggleman, B. (1996). Developmental regulation of zebrafish MyoD in wild-type, no tail and spadetail embryos. Development 122, 271-280.

Weintraub, H. (1991). The myoD gene family: nodal point during specification of the muscle cell lineage. Science 251, 761-766. 